\title{
Europa "underground"': enverdecimento do ser, Reforma da Vida, bruxarias e outros modos de pensar o espiritual
}

\author{
Underground Europe. Greening of the self, Reform of life, \\ witchcrafts and other ways of thinking the spiritual
}

\section{Joana Bahia}

Brasil. Universidade do Estado do Rio de Janeiro. Professora titular do departamento de Ciências Humanas e da Pós-Graduação em História Social da UERJ. Doutora em Antropologia Social pelo Programa de Pós-Graduação em Antropologia Social da Universidade Federal do Rio de Janeiro (PPGAS-UFRJ).IDORCID: http://orcid.org/0000-0002-2172-5022.E-mail:joana.bahia@gmail.com.

\section{Resumo}

Trato, neste artigo, sobre o modo como o movimento da Reforma da Vida colaborou para a construção de uma espiritualidade e novos modos de pensar o sujeito, que forjaram os elementos socioculturais de receptividade às religiosidades afro-brasileiras não apenas na Alemanha, mas em grande parte do contexto europeu, trazendo também problemas para a transnacionalização religiosa, em que ressurgem práticas do veganismo e outros modos de lidar com a construção religiosa do sujeito europeu sob grande influência das práticas espiritualistas e da chamada Nova Era.

Palavras-chave: Enverdecimento do Ser, Reforma da Vida, Espiritualidade, Religiões Afro-brasileiras, Transnacionalização Religiosa.

Termo utilizado por James Webb no livro The occult underground (1974), evidenciando que, em meados do século XIX, quando se imagina que a ciência e a razão haviam obtido seus maiores triunfos, há um surpreendente renascimento do ocultismo e do antirracionalismo. 


\section{Abstract}

This paper analyzes how the Life Reform movement collaborated in the construction of a certain spirituality and in new ways of thinking the individual, which forged the socio-cultural elements of receptivity to Afro-Brazilian religions not only in Germany, but also in a large part of Europe, while also resulting in problems to religious transnationalization, wherein vegan practices and other ways of dealing with the religious construction of the European individual under great influence of spiritualist practices and the so-called new era reappeared.

Keywords: Greening of the Self, Life Reform, Spirituality, Afro-Brazilian Religions, Religion Transnationalization.

\section{INTRODUÇÃO}

Desde os anos 1960, a prática e a expansão das religiões afro-brasileiras (umbanda e candomblé) na América Latina (Uruguai e Argentina) foram estudadas por Frigerio (1999), Segato (1991, 1994, 1997) e Oro (1998). A partir de 1970, elas cruzam o Atlântico e expandem-se em Portugal (CORRÊA, 2016; GUILLOT, 2011; PORDEUS JÚNIOR, 2009; SARAIVA, 2010), encontrando-se hoje na Espanha, Bélgica, Itália (CAPPONI, 2018; GOLFETTO, 2018), França (CAPONE; TEISENHOFFER, 2001-2002; TEISENHOFFER, 2007), Alemanha (BAHIA, 2013, 2014; BONILLA, 2011; ROSSBACH DE OLMOS, 2009; SILVA, 2014; SPLIESGART, 2011), Áustria e Suíça (BAHIA, 2013, 2014; SILVA, 2014), e estando ainda presentes nos Estados Unidos, no Japão e na Rússia (expansão do Ifá). Essas religiões entraram em Portugal no final dos anos 1970, com a abertura social e política trazida pela lei de liberdade religiosa, sancionada em 2001, instaurada com os ecos, em 1974, da Revolução de 25 de Abril (também conhecida como Revolução dos Cravos ou Revolução de Abril) (PORDEUS JÚNIOR, 2009; SARAIVA, 2010). Houve intensificação da umbanda e do candomblé a partir da década de 1980, período no qual alguns brasileiros instalaram-se no país como sacerdotes. 
Trabalho, há alguns anos, com transnacionalização religiosa na Europa, em especial Alemanha (BAHIA, 2013, 2014, 2015, 2018) e Portugal (BAHIA, 2013, 2014, 2015), e muitas pessoas até hoje me perguntam como é possível haver portugueses nas religiões afro-brasileiras (BAHIA, 2015; CORRÊA, 2016; GUILLOT, 2011; PORDEUS JÚNIOR, 2009; SARAIVA, 2010), assim como tantos europeus frequentando essas religiosidades em outros países capoeira (BRITO, 2020), santeria (ROSSBACH DE OLMOS, 2009) e candomblé na Alemanha (BAHIA, 2014); umbanda na França (TEISENHOFFER, 2007) e na Alemanha (BAHIA, 2013, 2014, 2015, 2018; SILVA, 2014). Em que medida a bruxaria, a crença em espíritos e o catolicismo popular (BASTOS, 1985; ESPÍRITO SANTO, 1984; LOPES, 1995) são elementos que podem explicar a receptividade às religiosidades afro-brasileiras (SARAIVA, 2010), bem como suas limitações, as idas e vindas dos espíritos, com novas traduções e agências espirituais, como é o caso do espírito da pombagira Maria Padilha, em Portugal (BAHIA, 2020)²? No caso desse país, cabe lembrar que a crença em práticas de bruxaria (MARTINS, 1997; MONTENEGRO, 2005), a penetração e o crescimento do espiritismo, somados às práticas de um forte catolicismo popular, bem como à sua reprodução e continuidade em muitas áreas do país, em especial no norte (GRACINO JÚNIOR, 2012), foram fatores importantes para pensar a "aceitação", por parte dos portugueses, das práticas rituais das religiões afro-brasileiras.

Este artigo trata sobre o modo como o movimento da Reforma da Vida colaborou para a construção de uma espiritualidade e novos modos de pensar o sujeito, que forjaram os elementos socioculturais de receptividade às religiosidades afro-brasileiras não apenas na Alemanha, mas em grande parte do contexto europeu, trazendo também problemas para a transnacionalização religiosa, em que ressurgem práticas do veganismo e outros modos de lidar com a construção religiosa do sujeito europeu sob grande influência das práticas espiritualistas e da chamada Nova Era.

\footnotetext{
2 Pombagiras têm circulado por séculos entre a Península Ibérica e o Brasil colonial, trocando novos significados, à medida que as religiões afro-brasileiras iam para Portugal transportadas por migrantes brasileiros (ESPÍRITO SANTO, 1984; BETHENCOURT, 2004).
} 
Cabe lembrar que, a partir da década de 1970, as religiões afro-brasileiras chegam, com seus recursos espirituais, a um público europeu, ao mesmo tempo que promovem seu patrimônio cultural originalmente africano como marca de autenticidade. Os adeptos europeus dedicam-se a uma prática religiosa "estrangeira", que, por meio da iniciação, permite-lhes um renascimento espiritual e a construção de novas identidades. Nesse sentido, a circulação das religiões afro-brasileiras favorece a emergência de novas filiações, oscilando entre etnicidades e universalismos, gerando novas identidades, na multiplicidade de novas paisagens do mundo contemporâneo (APPADURAI, 2004). Essas dinâmicas, contudo, não conduzem, necessariamente, à homogeneização do mundo globalizado, mas ao ressurgimento das especificidades locais a partir de certa "desterritorialização dos bens simbólicos em circulação" (CAPONE, 2004, p. 20).

Se, por um lado, há uma reorientação cultural na iniciação no candomblé, uma possibilidade de ressemantização (BASTIDE, 1971) e talvez uma "desetninização de uma herança afro e brasileira”, por outro há uma nova construção identitária europeia, com novas possibilidades e múltiplas identidades. Não obstante as raízes culturais das religiões afro-brasileiras serem marcadas por suas origens africanas, relacionadas com a preservação e a resistência das culturas dos negros escravizados e trazidos pelo Atlântico (GILROY, 2001), essas práticas religiosas não são patrimônio exclusivo dos afrodescendentes. Na verdade, elas se abriram à participação de um público branco e de várias origens sociais.

$\mathrm{Na}$ iniciação religiosa, de algum modo dá-se essa aproximação com a África, sendo possível o que Bastide (1971) denomina "Africanus sum". Contudo, quando os neófitos brancos africanizam-se, ao entrarem para o candomblé, não significa necessariamente que se tornam negros. A construção desse outro, dessas alteridades, é bem complexa em muitos casos, pois vai depender dos contextos em que esses grupos vão constituir-se e de suas relações, na complexidade social europeia, com sua história pós-colonial, os fluxos migratórios e as paisagens translocais (APPADURAI, 2004).

Se, por um lado, existe uma Europa “underground”, em que as práticas mágicas e os misticismos estiveram sempre presentes no imaginário popular 
e em sua própria história, havendo a possibilidade de reviver esses paganismos com a entrada recente de novas religiosidades, por outro, como lidar com um europeu que não tem laços com a África imaginária trazida por religiões como o candomblé?

A mediação do orixá, na experiência da possessão, reorganiza passado e presente, fazendo com que o sujeito se conecte ao divino, a um sagrado selvagem (BASTIDE, 1992), ou mobilize memórias importantes na produção de sua mediunidade (BAHIA, 2018). O corpo, as emoções e as conexões espirituais com os orixás/espíritos são parte desse aprendizado (STOLLER, 1989), somando-se a ele novos lugares, por onde será moldado esse ser mediúnico (BAHIA, 2015). Muitos evocam o Brasil como um lugar "natural do sincretismo e da mistura de povos", comparando-o a suas próprias origens étnicas, reconfigurando sua história com o candomblé.

Assim, para entendermos melhor essa construção sobre o passado, é preciso voltarmos à experiência romântica e ao modo como ela fabrica realidades e subjetividades no contexto europeu. Essa experiência molda sentimentos relacionados com o corpo e a natureza, que se, por um lado, aproximam-se dos elementos das religiosidades afro-brasileiras, por outro podem trazer conflitos e novos rearranjos religiosos.

\section{A (IR)RACIONALIDADE DO MUNDO: A "INTERNACIONAL OCULTISTA", OU NOVOS MODELOS DE PENSAMENTOS TRANSATLÂNTICOS}

O Romantismo (DUARTE, 2019), mais do que um movimento alemão, é um movimento cultural europeu, com influência também nas colônias europeias da época. Lowy (2008) afirma que o Romantismo é um ciclo longo, que começou em meados do século XVIII, indo até o século XXI, atravessando, efetivamente, todos os movimentos: o Simbolismo, o Surrealismo e a Beat Generation. Influenciou grande parte da vanguarda artística (ÁVILES, 2019) e manteve-se vital em toda a história da cultura moderna (LOWY, 2008). Teve vários precursores, sendo 
conectado a vertentes filosóficas, literárias e artísticas, que apresentavam, antecipadamente, motivos românticos em contextos iluministas e clássicos. São pré-românticos, na França, Diderot e Rousseau, e, na Inglaterra, Young, Shaftesbury, Gray e MacPherson (BRUSEKE, 2004). No Romantismo, existe sempre o sentimento de nostalgia, uma sensação trágica de que a modernidade está destruindo os valores em que se acredita. Entretanto, não é uma simples volta ao passado, mas uma retomada do passado em direção ao futuro (LOWY, 2008) ${ }^{3}$.

A era da industrialização é comumente associada à ideia de racionalização do mundo; entretanto, muitos movimentos religiosos, correntes ocultistas e apocalípticas constituíram-se em parte desse momento, tanto na América quanto na Europa.

Esses movimentos contribuíram para a criação de modelos de pensamento para a compreensão das mudanças sociais e políticas da sociedade industrial. Muitos buscavam, especialmente os ocultistas, uma junção com as ciências da natureza, evidenciando que as relações seculares poderiam ser interpretadas pela religião. Atualizaram interpretações sobre a relação entre corpo e matéria, alma e espírito, doença e saúde, morte e vida, individualidade e comunidade (WEBB, 1974; LINSE, 1996, 1998). Muitos relacionavam as ideias de energia e matéria com os modernos progressos da ciência, como as ondas magnéticas e a radioatividade, de modo que os espíritos poderiam materializar-se, e a própria ideia de evolução que rege a natureza reuniria mundos fragmentados. Muitos espíritas aplicavam a seu modo os métodos científicos ao campo do sobrenatural e produziram textos em que "psicologizavam as doenças", assim como os processos de cura, ao crer que os espíritos de pessoas mortas poderiam causar enfermidades (LINSE, 1996).

Nesse sentido, o ocultismo moderno seria a controversa aproximação entre religião e ciência, ou seja, entre os espíritas e os cientistas alemães, como o caso do médium HenrySladeedofísicoJohann KarlFriedrichZöllnerporocasiãode sua ida para Leipzig, em 1877 (TREITEL, 2004). Várias das sessões espíritas

\footnotetext{
3 Não pretendo igualar surrealistas a simbolistas; continuidades e descontinuidades marcam esse ir e vir dos românticos. Se alguns são nacionalistas, outros, não. Alguns são mais místicos, ocultistas; outros, ateus. Há muitas diferenças entre os vários movimentos artísticos, porém muitos, como Breton, identificam-se com um prolongamento do movimento, apontando "continuidades". "Nós somos a cauda do cometa romântico, mas somos uma cauda preênsil, como aquela do macaco” (LOWY, 2008, p. 16).
} 
de Slade foram presenciadas por cientistas de renome, como Wundt e Fechner, ambos pioneiros no campo da psicologia científica e da psicologia experimental, ocupando cátedras em Leipzig, em 1834 e 1875, respectivamente.

Os espíritas, os novos apóstolos e vários movimentos, como ocultismo, milenarismo, tendências apocalípticas, revitalização do protestantismo e cura das almas, concorrem com a plena industrialização. O período entre o século XIX e a metade do século XX é intitulado “underground da Europa”, compreendendo esse momento como resultante de uma crise de valores (WEBB, 1974). Entretanto, a ideia de "fuga de uma razão", na realidade, pode ser compreendida não como "crise de valores", mas como renovação da consciência religiosa. Pensamento apocalíptico, espiritismo e teosofia desenvolveram-se como tendências supranacionais, pan-europeias e transatlânticas (tendo os dois últimos como ponto de partida, os Estados Unidos), absorvendo tanto o ideário da direita quanto o da esquerda (LINSE, 1996).

Associações, como a dos Espíritas Alemães, tinham correspondentes na Dinamarca, Bélgica, Inglaterra, Rússia, França e também no Brasil e no México. A exemplo de publicações, surgem a Zeitschrift für Spiritismus, em 1904, o editorial espírita Oswald Mutze, em 1902 (Leipzig), que publica Über die Psychische Kraft des Weibes (Sobre o poder psíquico das mulheres), textos sobre sonambulismo, como Die Seherin von Prevost (A visionária de Prevost), de 1829, de Justinus Kerner, eventos como o $1{ }^{\circ}$ Congresso de Ocultistas Alemães, em 1898, em Berlim, e também um forte investimento na construção de liceus para formação educacional que se opunham às escolas dominicais eclesiásticas (o caso dos Children's Progressive Lyceums americanos, transplantados para a Inglaterra).

Vários desses movimentos atraíram não apenas as classes abastadas, havendo grupos que buscavam aproximações com as reformas sociais, artesãos, proletários e jovens de ambos os sexos, com participação expressiva de mulheres. Isto é, muitos se concebiam como parte de um movimento mais amplo, que abrangia também um sentido político. Assim, a melhoria de uma práxis individual levaria à consequente transformação do mundo (HEELAS, 1996). 


\section{REFORMA DA VIDA, OU "SELF-REFORM": O HOLISMO E A ARTE ORGÂNICA DE VIVER}

Tais ideias, que valorizam o indivíduo como motor da transformação, são oriundas do movimento da Reforma da Vida (KRABBE, 1998). A primeira vez em que o significado da Reforma da Vida apareceu foi na década de 1890 (BUCHHOLZ; LATOCHA; PECKMANN; WOLBERT, 2001)4, quando o movimento já tinha se espalhado em diferentes direções. Muitas publicações referentes a estética, religiosidade, novas ideias filosóficas sobre literatura, ciência, pedagogia, assim como emancipação e ideias de reforma social, foram agrupadas em torno da chamada Reforma da Vida. Várias dessas ideias inter-relacionavam-se de algum modo. O significado da Reforma da Vida refletiu-se nas concepções de arte da vida, nutrição, como e onde se vive (housing, circunstâncias de morar e viver) e práticas de saúde (LINSE, 1998).

As ideias de "volta ao futuro" e "arte orgânica de viver" foram atributos que definiram o movimento. Como característica de todo movimento social, a Reforma da Vida, como um todo, não era organizada, contendo diferentes grupos e associações que não concordavam entre si, tinham diversas influências, mas se relacionavam, por terem os mesmos objetivos. Muitos eram padres, médicos, ocultistas, profetas, $\operatorname{artistas}^{5}$, escritores, intelectuais e filósofos. Como exemplo, temos Kneipp, sacerdote católico, defensor do naturismo, que foi um dos ideólogos da hidroterapia. Foi diretor das termas de Bad Wörishofen e criador da Terapia de Kneipp, uma estratégia hidroterapêutica e dietética ainda praticada nos dias de hoje.

Nesse sentido, a natureza inspira um estilo de vida e uma cultura que valorizam o antialcoolismo, o vegetarianismo (coincidindo com o crescimento das cidades e o aumento do consumo de álcool, açúcar e carne), a prática

\footnotetext{
Há vários textos acadêmicos que mostram que muitos nazistas apropriaram-se de alguns aspectos da Reforma da Vida, entretanto não podemos reduzir um movimento tão complexo a esse episódio. Historiadores como Hugh Trevor-Roper e Thomas W. Laqueur são, em grande parte, os responsáveis pela veiculação desse tipo de interpretação. Muitos rediscutem essa questão, afirmando que, embora haja certas afinidades culturais, não se pode afirmar que houvesse alianças sociopolíticas mais efetivas entre os ocultistas e o Estado.

5 Sobre a participação de artistas no movimento, ver Kirchgraber (2003).
} 
desportiva, formas de viver e vestir, as práticas de nudismo, as curas naturais e a ideia de trazer a natureza para a cidade, como vemos nos jardins de Schreber (a chamada Gartenkolonie, prática comum até os dias de hoje).

Daniel Schreber, médico de Leipzig, propunha como solução para as camadas mais baixas da sociedade a existência de pequenos lotes de terra no meio da cidade, em que os adultos pudessem plantar verduras, frutas, e as crianças, brincar na natureza. A ideia de retorno à natureza é vista, assim, como questão de saúde. Esses jardins, atualmente, não têm a mesma característica, mas se constituem em parte da cultura alemã, existindo cerca de 4 milhões deles espalhados por toda a Alemanha. Em torno da ideia de retorno à vida rural, fundaram-se colônias, sendo as mais famosas Éden, Oranienburg e Monte Verità, além de muitos sanatórios.

A cooperativa vegetariana Monte Verità, fundada, em 1906, pela feminista anarquista Ida Hofmann ${ }^{6}$ e por Henry Oedenkoven, Gustav Gräser, Lotte Hattemer, Karl Gräser e Jenny Hofmann, na região italiana de Ticino, nos Alpes Suíços, foi visitada por Lenin e também por personagens mais ligados a esse tipo de movimento, como Hermann Hesse e Thomas Mann. Rapidamente, os intelectuais europeus demonstraram interesse pelo projeto e deram-lhe apoio. Pensadores consagrados, como Jung, Mircea Eliade, Otto Hesse, Kropotkin, Gross, Steiner, Arp, Joyce, Rilke, Mann, Frisch, Klee, Brecht, Stefan George, Isadora Duncan e outros, entre os quais vegetarianos, nudistas, teósofos, anarquistas, literatos e utopistas, passaram pelo Monte Verità?.

As doenças significavam a má influência da modernidade sobre o corpo e a alma. O ser humano poderia voltar à vida vegetariana por meio dos esportes,

\footnotetext{
${ }^{6}$ Ida Hofmann escreveu obras como A contribution to the female question e The importance of true theosophy, e compilou algumas notas conhecidas, como Notes towards the promotion of the vegetarian lifestyle. Também escreveu, junto com Henri Oedenkoven, um livro sobre o Monte Verità (SÁNCHEZ, 2001). Cabe ainda ressaltar que a conhecida astróloga Emma Costet de Mascheville, nascida em $1903 \mathrm{em}$ Haimhausen, na Alemanha, formadora de gerações de vários astrólogos brasileiros (como Antônio Bola Harres e Cláudia Lisboa), era sobrinha de Ida Hofmann, importante fato para sua formação educacional.

7 Monte Verità foi também um espaço de sincretismo religioso, a exemplo do Círculo de Eranos, centro de estudos mitológicos fundado pela holandesa Olga Fröbe-Kapteyn, teósofa próxima da escritora Ida Hofmann, ocultista e militante dos direitos das mulheres. Ela chegou ao Monte Verità em 1924 e, juntamente com o mitólogo Rudolf Otto, propôs a tarefa de analisar as religiões do Oriente e do Ocidente. Então, a partir de 1927, realizaram-se ali congressos anuais, aos quais estiveram presentes prestigiados estudiosos das religiões.
} 
da exposição à luz, do ar, com o que poderia combatê-las. A ideia de holismo, fundamental nesse movimento, lembra que todas as partes estão inter-relacionadas, não havendo separação entre corpo, espírito e alma. Vitalismo significa imaginação de uma vida, forças vitais, poder de uma vida enérgica contida no próprio ser humano e que organiza as defesas contra as doenças (BUCHHOLZ; LATOCHA; PECKMANN; WOLBERT, 2001). Como vemos, ginástica, esporte, massagens, aparelhos para novos tipos de ginástica, dança, beleza física, Wanderung (caminhada), especulações eugênicas de toda sorte, formas de cura e acesso a elas, formas de alimentação e medicamentos naturais seriam modos de combate às doenças. Mas se trata também do respeito à natureza, ao corpo como natureza, e às florestas, aos rios e a tudo que compõe o mundo no qual vive o ser humano e do qual ele depende.

Tais preocupações, porém, conectaram-se com questões políticas, em face do processo de urbanização, terminando por dar origem a diversos movimentos de reforma do solo urbano, como a planificação de cidades-jardins, impondo limites ao processo de pauperização das massas e gerando medidas capazes de incidir sobre as condições de habitação nas cidades. O corpo é concebido como algo nobre, como se fosse o próprio ser humano, sendo o nudismo algo natural, a cultura de um corpo livre opondo-se à ideia de pecado. Muitos ideólogos do movimento "retiram o sexo do corpo" e pensam-no como algo saudável, higiênico, instrumentalizando-o (BUCHHOLZ; LATOCHA; PECKMANN; WOLBERT, 2001, p. 103-114). Várias dessas ideias influenciaram o campo artístico, em especial a dança, promovendo o debate sobre a naturalidade do movimento, como vemos com Isadora Duncan. A reforma de hábitos, que pretendia tornar a vida cotidiana confortável e natural, tinha raízes no fim do século XVIII, quando os anti-iluministas já protestavam não apenas contra a Revolução Francesa e as invasões napoleônicas, mas também contra a influência francesa no dia a dia - contra o espartilho, a favor de roupas soltas e sapatos confortáveis e anatômicos.

Nesse caso, a self-reform levaria a uma reforma social mais ampla; a mudança da sociedade começaria com a mudança dos indivíduos. A reforma de si como reforma do mundo é uma das principais características do 
movimento New Age $e^{8}$, bastante difundido na Alemanha atual. Muitos dos aspectos da Reforma da Vida, como a ideia de holismo, de vitalismo e de como o próprio indivíduo, sob uma concepção que enfatiza uma "vida mais natural", cria sua energia vital, são retomados nesse movimento. Lembramos que, não obstante haver um grande movimento dessas práticas no país, a conexão com o esoterismo não é específica da Alemanha, mas o estímulo às práticas tradicionais rurais, promovido pelo Romantismo, sendo reafirmado no movimento da Reforma da Vida, certamente contribuiu para a facilidade de sua penetração.

Devemos lembrar a importância de Rudolf Steiner (filósofo, educador, artista e esotérico) na divulgação dessas práticas, atribuindo a esse aspecto uma legitimação especial em um país fortemente marcado por práticas rurais que resistiram às religiões "racionais" universalistas. Steiner também foi um dos idealizadores da antroposofia ${ }^{9}$ e das ideias da chamada Pedagogia Waldorf ${ }^{10}$. Seu trabalho foi bastante inspirador para o campo artístico, tendo influenciado o de Hilma af Klint de transformar o mundo invisível das sensações em algo tangível por meio da pintura.

Hilma entra para a Sociedade Antroposófica em 1920. No mesmo período em que produziu suas obras, estão as de Emma Kunz e Georgiana Houghton, que faziam também de suas experiências mediúnicas e místicas fonte de material para seus trabalhos. Nessas artistas, vemos diferentes modos de pensar o mediúnico. A ideia de "I am a radio", da artista suíça Jeanne Natalie Wintsch, mostra a existência de ondas invisíveis, que nos rodeiam como um transmissor. Somos receptores e transmissores ao mesmo tempo. Nesse sentido, a função do médium como mediador constrói-se como experiência subjetiva (ALTHAUS;

\footnotetext{
8 Autores como Lewis e Melton (1992) e Ferreux (2000) afirmam a dificuldade em definir o New Age, movimento difuso, múltiplo, difícil de apreender e que toma o retorno à natureza, ao qualitativo, à autenticidade, ao desenvolvimento pessoal, à espiritualidade, simbolizando a busca da criação de um mundo alternativo e holístico.

9 Cabe lembrar que, no Brasil, as várias sociedades antroposóficas surgem a partir de 1939, promovendo o estudo das obras de Steiner e, consequentemente, expandindo suas práticas terapêuticas, baseadas na ideia de que a narrativa biográfica é fundamental no processo de cura (BASTOS; PEREIRA, 2016).

${ }_{10}$ Steiner introduz a Pedagogia Waldorf em 1919, em uma escola para filhos de operários da fábrica de cigarros Waldorf-Astoria, tendo como base principal a ideia de uma educação holística.
} 
MÜHLING; SCHNEIDER, 2019). Para Wintsch, inspiração (inspirare) e imaginação (imago) estariam presentes nas experiências artísticas e mediúnicas. A autora entende inspiração como algo produzido por estados alterados de consciência, como sonhos, transes, visões, meditação e drogas. Nesses casos, o artista médium/mediador acredita que a própria ideia de criatividade pode ser compreendida no contexto da experiência da mediunidade (ALTHAUS; MÜHLING; SCHNEIDER, 2019).

O movimento teosófico e o cisma do Novo Pensamento no campo católico (em especial com ênfase na liberdade de crença e nos processos de cura espiritual), ambos movimentos de fins do século XIX (LINSE, 1996, 1998), foram os responsáveis pela contribuição à visão de mundo que conforma o desenvolvimento da Nova Era nos anos 1970 (ALEXANDER, 1992). Muitos dos ideólogos do cisma e teósofos são apreciadores das obras do austríaco, médico e hipnotizador Franz Anton Mesmer, e do suíço, filósofo e místico Emanuel Swedenborg (ALEXANDER, 1992). A ideia de uma energia transmitida pela mente tem base no conceito indiano de Akasha, referência comum a vários místicos e adeptos da Reforma da Vida em fins do século XIX. Esse mesmo conceito de energia é retomado nas práticas espiritualistas da Nova Era (LEWIS; MELTON, 1992). Na Reforma da Vida, muitos tomam os conhecimentos orientais, especialmente de Índia, China e Japão, enfatizando a relação entre as práticas alimentares e as espirituais (BUCHHOLZ; LATOCHA; PECKMANN; WOLBERT, 2001).

Madame Blavatsky e Henry Steele Olcott fundaram, em 1875, a Sociedade Teosófica, em Nova York, convocando vários líderes hindus a permanecerem nos Estados Unidos, introduzindo a filosofia budista e a hindu. Posteriormente, o movimento também se desenvolve pela troca intelectual nas áreas da psicologia humanista, em especial entre o meio acadêmico americano e o alemão no período entreguerras, e, posteriormente, com a psicologia transpessoal (que enfatiza a dimensão espiritual da experiência) (LEWIS; MELTON, 1992).

Atualmente, é evidente a importância dessas práticas no cotidiano alemão, permanecendo a referência às filosofias orientais e uma proximidade com práticas afro-cubanas e brasileiras. Observamos que a presença das religiões afro-brasileiras evoca uma Europa pagã, em que os vários participantes agregam suas crenças à 
abertura que encontram nas religiões afro-brasileiras. A ideia de natureza e o respeito e a proximidade a uma concepção tradicional de conhecimento (CASTELLS, 1999), que conduz a uma ressignificação do corpo (BARROS; TEIXEIRA, 2000), atraem os europeus para essas religiões (BAHIA, 2014). Submetermo-nos à natureza e ao corpo torna-nos mais próximos da tomada de consciência de nossa dimensão cosmológica (CASTELLS, 1999), que é reconduzida pela busca, por parte dos alemães, dos saberes populares, reinventando suas tradições.

\section{HOMO SENTIMENTALIS, OU O ENVERDECIMENTO DO SER: NOVA ERA, UMBANDA E CANDOMBLÉ}

Kundera (1990) evoca a ideia de uma Europa supostamente fundada no racional, mas também do europeu como um homem que experimenta sentimentos, porque os valoriza, ou seja, sentimentos são compreendidos como valor. Contudo, experimentá-los pode transformá-los em simulacro, pela impossibilidade de externalização da interioridade. De que modo essa interioridade é construída se o sujeito está ciente de que a consciência de si é fundamental para se reconectar com o mundo? Como externalizar algo que, a princípio, torna-se simulacro por sua mesma impossibilidade? Tarô no parque, homeopatia, psicoterapias diversificadas, acupuntura e outras práticas mais ou menos orientalizadas cercam esse sujeito sentimental, em que a necessidade de se reconectar faz-se urgente, mesmo que se reconstrua como simulacro.

Obem-estar do indivíduo, expresso em uma espécie de consciência corporal, está presente nas práticas contemporâneas da chamada Nova Era. Revistas como a Körper, Geist Seele (KGS). Gesundheit, Lebenshilfe und Inspiration (Corpo, espírito e alma. Saúde, autoajuda e inspiração) mostram essa correlação como fundamental na sociedade alemã, proliferando, sob o epíteto de esotérico, gurus, profetas, tarólogos e outros tipos de mentores, que garantem o ideal holístico. Temas como Vertrauen (confiar), Selbstvertrauen (autoconfiança), referidos na lógica hinduísta, são encontrados paralelamente à força dos cristais, ao serviço astrológico, à meditação, às práticas reikianas, homeopáticas 
e energéticas em geral, e também aos aconselhamentos psíquicos e espirituais. Um mundo de workshops, consultórios, produtos ecológicos e mercado bio são parte do cotidiano alemão, especialmente de suas camadas sociais médias. Mas, para alguns alemães, todo esse romantismo é ciência e nunca foi espiritualidade; tudo se conecta para apaziguar as incertezas do self.

Golfetto (2018; [2020]) mostra de que modo a ideia de self, presente em práticas como Reiki, meditação, massagens terapêuticas e ioga, é importante para a compreensão do universo do candomblé na Itália. Há uma grande aproximação com o budismo e uma grande circulação, nas terapias holísticas presentes no cotidiano de trabalho dos pais e mães de santo, de praticantes analisados pela autora. Há também os casos em que o conhecimento das terapias é usado para pensar o próprio candomblé.

Durante a entrevista, Chiara explicou o processo de autodescoberta que tem sido possível pelo Candomblé: descobrir cada juntó é descobrir de que energias o indivíduo é feito e, consequentemente, descobrir algumas partes de seu próprio caráter, suas "facetas". O processo de descoberta e autoconsciência é também um processo de aceitação: como Chiara declara, "aceitar seu orixá pessoal é aceitar a si mesmo". Portanto, o caminho do candomblé é entendido como um processo de desenvolvimento pessoal (GOLFETTO, 2018, p. 274).

Sobre esse universo terapêutico, que circula tanto entre as práticas de alguns pais e mães de santo quanto entre os praticantes e iniciados, há também os casos analisados por Teisenhoffer (2007), na França, e por Bahia (2018), na Alemanha. Se, por um lado, a proximidade com a dança e o ritual gera grande sentimento de bem-estar, por outro, algumas pessoas não entendem claramente o que essas mudanças são e desistem da religião quando encaram a possessão (BAHIA, 2018). Outros entendem que, a fim de experimentar esse novo corpo, necessitam tornar-se parte da religião (HAGEDORN, 2006).

Outra questão importante é o vegetarianismo. Este é atual na sociedade alemã e crescente em todo o mundo, sendo um dos pontos cruciais em muitos casos de alemães que passam a frequentar as religiões afro-brasileiras, questionando a comida de santo, o uso de carne no preparo de certos pratos ou mesmo 
a ideia de abate religioso. Há o caso de uma filha de santo da umbanda, na Alemanha, que não queria comer carne, mesmo sabendo que era a comida de sua pombagira. Na lógica da religião, a comida ingerida é compreendida como axé, sendo benéfica à saúde, e as práticas corporais são necessárias ao alimento da alma, indissociável do alimento preparado e ingerido pelo corpo do neófito, esteja ele em estado de transe ou não. Em muitos casos, quando as práticas rituais são iniciadas, há uma mudança. As danças, os rituais, o uso de ervas não são problema, até que alguém confronte o transe e o uso de sangue como parte da lógica do sacrifício. Muitos desistem da religião nesse momento. É nos momentos de desentendimento entre o pai de santo e os que desistem da religião que os elementos contrastantes se tornam claros, surgindo os marcadores de identidade, quando são acusados de pensar como "europeus", querendo um "candomblé vegetariano, que só existe em suas mentes”. Aspectos como a autoridade do pai de santo como líder espiritual, a ideia de família de santo e o modo como essa relação tem forte controle sobre o indivíduo e a comensalidade entre homens e deuses, que envolve o uso da carne, são também muitas vezes difíceis para os alemães entenderem e aceitarem. Os aspectos sobre vegetarianismo não apareceram apenas em minha etnografia (BAHIA, 2014) ${ }^{11}$. Conversando com pesquisadoras como Capponi (2018; [2020]), Golfetto (2018, [2020]) e Silva (2014) em seus vários campos na Europa, atestei que elas também tiveram de lidar com essas questões e com a interface entre o conhecimento afro-religioso e as terapias e os conhecimentos próximos à Nova Era.

Para muitos adeptos do candomblé e da umbanda, no Brasil, a comida de santo tem axé, e isso beneficiaria mesmo um filho de santo vegetariano, pois não é apenas uma comida, mas um alimento indissociável para a alma e o corpo, que se transformou ao ter contato com o mundo espiritual. Com o crescimento gradual do veganismo no Brasil, das correntes do pensamento ecológico, das práticas de uma teologia (católico-franciscana) ecologista,

\footnotetext{
${ }^{11}$ O gosto pela carne, presente no cardápio brasileiro, sistematicamente tem dado lugar ao aipim frito e à salada na comensalidade após os rituais no decorrer de meu trabalho de campo. Mas, observando melhor outras realidades, dependendo dos pais e das mães de santo e da relação com sua comunidade, e havendo maior presença de europeus como público, isso pode interferir no modo como o terreiro é conduzido e na produção da comida que é feita para a assistência após as festas de santo.
} 
como a de Leonardo Boff (CARNEIRO, 2019), todas essas ideias têm se refletido em algumas práticas: a adoção do culto de Yezam pela Dobanna Boressa Mãe Solange Buonocore, em São Paulo, sob influência do cubano Alawowo Messekan Meyé Samyer Phurull (CARNEIRO, 2019) ${ }^{12}$; a importância das ervas, na visão do famoso babalossaim Pai Agenor Miranda; e formas novas de reetnicizar a chamada comida de santo ou de criar possibilidades veganas, como com o acarajé. Há pessoas que pertencem à religião e que também transitam pelo universo vegano e/ou das terapias naturais, e outras que se incomodam com a ideia do sangue, mesmo não sendo vegetarianas (CARNEIRO, 2019).

Nesse sentido, novos nexos são construídos, levando-se em consideração a realidade local e, em termos gerais, a europeia. Como exemplo, na Alemanha, os workshops, folhetos e textos produzidos por Mãe Habiba. Um dos vários workshops de Mãe Habiba foi realizado na região de Ravensbruck, um campo de concentração no período da Segunda Guerra, na Alemanha. É óbvio que essa revisão histórica é uma atualização, em termos locais, do modo como são interpretadas a religião e a realidade do lugar. De acordo com o que traduz em seu livro como "Systemische Prozessgestaltung" (KRESZMEIER, 2008), os traumas da guerra e outras questões históricas afastaram os alemães de sua própria natureza e, por que não dizer, de seus próprios espíritos? Nesse sentido, o Brasil (com seu know-how) lhes traria de volta o contato com essa natureza, ancestralidade e espíritos. Lembraria aos alemães o que é viver (título do workshop: Lebendiges Erinnern - Lembrando de viver), evocando mais a ideia de natureza e dirimindo o nome "religião", que em momento nenhum aparece em suas descrições.

Em um dos folhetos, há o que se chama Fórum das Águas Doces (Forum derSüßen Wasser), uma clara alusão tanto a seu orixá de cabeça, Oxum, quanto à ideia do feminino, que evoca os espíritos das mulheres que morreram em Ravensbrück, que, a partir de 1939, foi considerado um campo de concentração predominantemente feminino, tendo somente em 1941 a entrada de homens e, posteriormente, em 1942, a de crianças e adolescentes.

\footnotetext{
${ }_{12}$ Fato novo, que é bastante criticado pela comunidade de terreiros, pois há uma desvinculação entre os caminhos de Exu e de Ossaim e, consequentemente, entre oró e sassaim (CARNEIRO, 2019). Mesmo que muitos seguidores do candomblé sejam adeptos de terapias holísticas, a mistura entre ambas as práticas, ou entre essas lógicas de pensamento, é bastante criticada.
} 
A ideia de água como fonte da vida (Lebenswasser), a ideia de comunidade (Gemeinschaft) e outros elementos da natureza são temas pertinentes em seus workshops e textos, que descrevem os orixás sem nomeá-los e sem usar o nome umbanda ou religião afro, não permitindo também o uso de imagens de caboclos (índios) e pretos-velhos (escravos), pois considera esse "hábito brasileiro kitsch", baseando seu ponto de vista na essencialidade espiritual e não se detendo no que considera "apenas aspectos materiais". Silva (2014) analisa o discurso da mãe de santo, mostrando como ela se apropria da realidade local e de que modo essa relação com um conhecimento primordial sobre a natureza foi desconstruída

[P]ensando a situação da Alemanha - um país profundamente traumatizado com o recente passado do Shoah -, podemos nos perguntar se aprenderemos algo com este momento da história brasileira. Nesta terra, os antigos deuses e deusas têm sido mais cruéis, que não podemos mais deles nos lembrar. A mãe de santo austríaca Ya Habiba de Oxum Abalô afirma o pensamento acima com as seguintes palavras: gostaria de falar que a nossa comunicação com a essência do nosso espírito foi de uma maneira violenta, expulsando o saber. O que é uma realidade nossa... O nosso contato com a natureza e com nosso espírito da natureza foi interrompido. (SILVA, 2014, p. 290)

Se a umbanda é um espelho, segundo Silva (2014), esse espelho também serve para os adeptos alemães pensarem sua própria realidade, em que o sujeito, ao melhorar seu caminho espiritual, estaria mais apto a lidar com a sociedade. A ideia de bem-estar do indivíduo, expressa em uma espécie de consciência corporal, está presente nas práticas contemporâneas da chamada Nova Era e é recriada pela umbanda, em que seus espíritos ajudam o indivíduo a seguir um caminho espiritual, tendo o corpo como suporte para isso.

\section{À GUISA DE CONCLUSÃO: OS NOVOS “HEILPRATIKERS”}

Muitos pais e mães de santo entrevistados na Alemanha que atendem individualmente, apesar de terem vínculos com terreiros no Brasil, não 
construíram suas trajetórias com a formação de templos na Europa. A maioria de suas práticas está relacionada com a umbanda e o candomblé, mas com diversas abordagens e misturando diferentes tradições. Muitos pais de santo trazem o conhecimento de outros saberes mágicos, como a Wicca, também fazem formação em Reiki, frequentam o Santo Daime e mantêm contato com práticas orientais e asiáticas que tanto podem ter sido trazidas por clientes quanto pelo contato com outras culturas pelas quais circulam e promovem traduções por ocasião de consultas individuais ou ao promoverem workshops na Alemanha ${ }^{13}$. A proximidade de alguns pais de santo com a Wicca facilita a comunicação com os europeus, pois estes podem praticar rituais simples e de mais fácil compreensão, como curas e encantamentos. Os rituais de alta magia não incluem muitos pratos elaborados, assim como os rituais afro-brasileiros. Estes requerem horas de preparação e muitas vezes exigem ingredientes exóticos, comprados em mercados africanos ou asiáticos. Nesse sentido, a Wicca não requer tantas proibições alimentares ou sexuais, como a umbanda e o candomblé.

Alguns pais de santo brasileiros entrevistados evidenciam que o know-how brasileiro é um dos mais completos, e de fato esse conhecimento vem do Brasil e pode ser acessível a todos, dependendo da disposição daqueles que querem nele aprofundar-se. Um entrevistado em Hamburgo lembra que ser pai de santo resume funções em que se levam anos para obter conhecimento na Alemanha: Heilpraktiker e Jäger ${ }^{14}$. Ou seja, ser pai de santo brasileiro é uma mistura de médico alternativo conhecedor das práticas tradicionais (homeopatia, acupuntura, terapia com cristais, Reiki) e do conhecimento acumulado

\footnotetext{
13 Sabemos que a cultura alemã, por meio do movimento Reforma da Vida, mantém trocas com as culturas orientais e asiáticas de diversos matizes desde o século XIX. O que, por um lado, facilita a entrada das religiões afro-brasileiras, promovendo um diálogo com o mundo da natureza, por outro aproxima os pais e as mães de santo de um universo de práticas alternativas que se encontram disponíveis em todo o território alemão com muita facilidade.

${ }^{14}$ Não quero afirmar que não haja limites e problemas nessa transnacionalização, sendo o abate religioso um deles, pois é proibido pela legislação alemã (ROSSBACH DE OLMOS, 2009). O manuseio do animal na Alemanha, é possível apenas para aqueles que têm licença de caçador. O uso de ervas deve também se restringir ao conhecimento do Heilpraktiker, o que reduz o uso do enorme estoque de conhecimento prático sobre banhos, infusões e combinações entre plantas e comidas presentes nas religiões afro-brasileiras. A disposição do conhecimento do Heilpraktiker reduz o acervo mágico dos pais de santo, em especial daqueles que se inserem na burocracia do Estado alemão e adquirem a licença de Berater (conselheiro/consultor), pois só podem usar as ervas autorizadas por esse sistema, que está bastante aquém do sistema cosmológico brasileiro.
} 
de um caçador, porém com a vantagem de aprender isso no ambiente em que se cresce, quando ainda se é crianç $\mathrm{a}^{15}$, no Brasil, e dotado de um conhecimento do pensamento iorubá, em que outras línguas são necessárias para isso (até para lidar com rituais que envolvem animais e plantas).

O que alguns entrevistados mostram é que, de todo modo, esse conhecimento acumulado em anos pode tornar-se móvel e transitar por diferentes contextos, promovendo trocas até mesmo no mundo islâmico, em que o uso de categorias populares desse universo pode ter alcance espiritual no universo da diáspora africana. Muitos pais de santo, diante da facilidade de mobilidade geográfica, tanto circulam suas práticas entre diferentes países e culturas quanto movem pessoas e objetos em sua direção, em uma espécie de sacralização de diferentes heranças (MEYER; WITTE, 2013), porém com novas misturas.

Sabemos que uma das marcas alemãs da Reforma da Vida encontra-se na Naturheilkunde, na homeopatia e na confrontação entre a medicina moderna e os Naturheilpraktiker - práticos que curam usando formas naturais e que sobreviveram com reconhecimento formal até os dias de hoje (DUBAR; LALOY, PAIVA; THOEMMES, 2015). Parte desses conhecimentos foi comercializada, como a Weleda, marca de medicamentos antroposóficos mundial. Todas as substâncias são extraídas da natureza e têm como princípio fundamental a ideia de estimular as forças curativas do próprio corpo (MEDICINA..., s. d.). Esse aspecto remete à força dos conhecimentos populares, que se acumularam desde remotas épocas, e conecta-se com a importante questão da bruxaria e dos movimentos religiosos derivados de visionários, profetas e ocultistas (LINSE, 1996; TREITEL, 2004; WEBB, 1974).

Entre as influências mais relevantes desse movimento na Alemanha, o mais representativo é o recente discurso ecológico (BUCHHOLZ; LATOCHA; PECKMANN; WOLBERT, 2001), que Castells (1999, p. 113-133) chama de "enverdecimento do eu". Segundo o autor, o que unifica o movimento do ambiente é uma temporalidade alternativa, que pede à sociedade e às instituições que aceitem a realidade do lento processo evolutivo de nossas espécies em

\footnotetext{
${ }^{15}$ Em geral, no candomblé, as crianças podem ser iniciadas e têm importante responsabilidade no aprendizado do conhecimento religioso (CAPUTO, 2012).
} 
seu ambiente. Para além das limitações criadas por nossa submissão ao tempo, tal como definido pelo relógio, ainda experimentado pela maioria das pessoas no mundo, verifica-se que uma histórica disputa sobre uma nova temporalidade está tomando lugar entre a anulação do tempo em redes de computadores e a realização de um tempo glacial, ao se tornar consciente de sua própria dimensão cosmológica (self cosmológico). Por meio dessa disputa sobre a apropriação da ciência, do espaço e do tempo, os ecologistas induzem a criação de uma nova identidade - uma identidade biológica, uma cultura do humano como componente da natureza. Essa identidade sociobiológica não implica negar a cultura histórica. Os ecologistas respeitam as culturas populares e a autenticidade cultural de várias tradições.

Nesse sentido, o "Africanus sum" (BASTIDE, 1971) torna-se complexo, na medida em que a realidade etnográfica nos mostra múltiplos atores e questões no contexto europeu. Será que bruxas, natureza, espíritos locais, memórias familiares, corporais e translocais produzirão uma semântica do feitiço? Do místico? Misticismos e bruxarias foram amplamente descritos na historiografia colonial, evidenciando essas relações entre Brasil e Portugal (CALAINHO, 2008; SOUZA, 1986), presentes em solo português (BASTOS, 1985; BETHENCOURT, 2004; ESPÍRITO SANTO, 1984; MONTENEGRO, 2005; SARAIVA, 2013) - amplamente descritas por De Martino (1959 apud Capponi, 2018), e Ginzburg (2012), na Itália, e Favret-Saada (1977), na França -, nos fluxos migratórios dos alemães para o Brasil (BAHIA, 2000) e, certamente, em grande parte da Europa (BURKE, 2010; LE GOFF, 2007; LEVACK, 1988).

Em um relato sobre um despacho encontrado em uma área próxima a Milão, Capponi (2018) mostra como o imaginário histórico do feitiço é acionado para entender a oferenda. Conforme descreve a autora:

A cena que o artigo descreve como "perturbadora" ou "macabra" contém elementos que ressoam com o imaginário de bruxas, sabá e elementos similares presentes na tradição folclórica italiana, mas também com casos de seitas satanistas, símbolos esotéricos e sacrifícios animais e humanos que foram superexpostos pela imprensa nacional e internacional nas últimas duas décadas. 
Assim, o misticismo europeu, presente na própria história europeia, a possibilidade de agregar elementos de outros conhecimentos religiosos e ressemantizá-los, evidenciando o aspecto criativo e produtor de sentidos peculiar ao universo afro-religioso, a proximidade com o pensamento romântico produtor de misticismos e modos alternativos de pensamento, um supermercado religioso com um cardápio de elementos da Nova Era agregados a ideias ecológicas sobre o humano e sua relação com o tempo e o espaço (CASTELLS, 1999) são elementos que tornam possível a entrada dessas religiões no contexto europeu, trazendo também questões e impasses àqueles que se veem diante desse sagrado e tornam-se parte desse "Africanum sum" (BASTIDE, 1971). O contato com esse divino traz memórias corporais, avivadas pelas emoções, histórias familiares ligadas ao próprio imaginário europeu místico, mas também nos apresenta, simultaneamente, a desetnicização e etnicidades reelaboradas, em que esse ser africano se, por um lado, remete-nos à celebração de um Atlântico negro (GILROY, 2001), por outro, nos conduz a outras paisagens (APPADURAI, 2004).

\section{REFERÊNCIAS BIBLIOGRÁFICAS}

1. ALEXANDER, Kay. Roots of the New Age in perspectives on the New Age. Nova York: State University of New York, 1992.

2. ALTHAUS, Karin; MÜHLING, Mathias; SCHNEIDER, Sebastian. World receivers: Georgiana Houghton, Hilma af Kint e Emma Kunz. München: Lenbachhaus \& Himmer, 2019.

3. APPADURAI, Arjun. Dimensões culturais da globalização: a modernidade sem peias. Lisboa: Teorema, 2004.

4. ÁVILES, Iván Gómez. Esoterismo y arte moderno: una estética de lo irracional. Madri: Ediciones Assimétricas, 2019.

5. BAHIA, Joana. As religiões afro-brasileiras em terras alemãs e suíças. Lisboa: ICS: Universidade de Lisboa, 2013. (Working paper).

6. BAHIA, Joana. Orixás em trânsito: o candomblé em Portugal. In: SILVA, Isabel Côrrea da et al. Ciências sociais cruzadas entre Portugal e o Brasil: trajectos e investigações no ICS. Lisboa: Imprensa de Ciências Sociais, 2015. p. 375-390. 
7. BAHIA, Joana. O tiro da bruxa: identidade, magia e religião na imigração alemã. Rio de Janeiro: Garamond, 2000.

8. BAHIA, Joana. The Romanticism of the Oyá: feelings, bodies, memories, and the multiple space-times of the medium. In: WORKSHOP SKILL AND SCALE IN TRANSNATIONAL MEDIUMSHIP, 2., 2018, Colônia/Siegen. Anais [...]. Cologne/Siegen: a.r.t.e.s. Graduate School for the Humanities Cologne, 2018.

9. BAHIA, Joana. Under the Berlin sky: candomblé on German shores. Vibrant, Brasília, v. 11, n. 2, p. 327-370, 2014.

10. BAHIA, Joana. Where do the prostitutes pray? On travestis, mães de santo, pombagiras ad post colonial desires. In: OOSTERBAAN, Martijn; VAN DE KAMP, Linda; BAHIA, Joana (ed.). Global trajectories of Brazilian religion: lusospheres. Grã-Bretanha: Bloomsbury Academic, 2020. p. 101-116.

11. BARROS, José Flávio Pessoa de; TEIXEIRA, Maria Lina Leão. O código do corpo: inscrições e marcas dos orixás. In: MOURA, Carlos Eugenio Marcondes de (ed.). Candomblé: religião de corpo e alma. Rio de Janeiro: Pallas, 2000. p. 103-138.

12. BASTIDE, Roger. As religiões africanas no Brasil. São Paulo: Edusp, 1971. v. 1-2.

13. BASTIDE, Roger. O sagrado selvagem. Cadernos de Campo, São Paulo, v. 2, n. 2, p. 143-157, 1992.

14. BASTOS, C. Bruxas e bruxos no Nordeste Algarvio. Trabalhos de Antropologia e Etnologia, Porto, v. 25, n. 2-4, p. 285-295, 1985.

15. BASTOS, Raquel Litterio; PEREIRA, Pedro Paulo Gomes. Bildung como cura: a terapia biográfica na antroposofia do Brasil. Debates do NER, Porto Alegre, v. 1, n. 29, p. 151-178, 2016.

16. BETHENCOURT, Francisco. O imaginário da magia: feiticeiras, adivinhos e curandeiros em Portugal no século XVI. São Paulo: Companhia das Letras, 2004.

17. BONILLA, Yolanda Sol Montoya. "Fazendo, olhando, adaptando": Ilé Obá Sileké: candomblé brasilero en Berlín. Marburg/Lahn: Förderverein "Völkerkunde in Marburg", 2011. (Reihe Curupira Workshop).

18. BUCHHOLZ, Kai et al. (org.). Die Lebenreform: Entwürfe zur Neugestaltung von Leben und Kunst um 1900. Darmstadt: Katalog zur Ausstellung im Institut Mathildenhöhe Darmstadt, 2001.

19. BURKE, Peter. Cultura popular na Idade Moderna: Europa, 1500-1800. São Paulo: Companhia das Letras, 2010.

20. BRITO, Celso de. The constitution of a transnational Sphere of transcendence: the relationship between the irmãos Guerreiros Capoeira Angola Group and Ilê Obá Silekê in Europe. In: OOSTERBAAN, Martijn; VAN DE KAMP, Linda; BAHIA, 
Joana. Global trajectories of Brazilian religion: lusospheres. Grã-Bretanha: Bloomsbury Academic, 2020.

21. BRUSEKE, Franz Josef. Romantismo, mística e escatologia política. Lua Nova, São Paulo, n. 62, p. 21-44, 2004.

22. CALAINHO, Daniela Bueno. Metrópole das mandingas: religiosidade negra e Inquisição portuguesa no Antigo Regime. Rio de Janeiro: Garamond, 2008.

23. CAPONE, Stefania. À propos des notions de globalisation et transnationalisation. Civilisations, [s. l.], v. 51, n. 1-2, p. 9-22, 2004.24.

24. CAPONE, Stefania; TEISENHOFFER, Viola. Devenir medium à Paris: apprentissage et adaptation rituelle dans l'implantation d'un terreiro de candomblé en France. Psychopathologie Africaine, Dakar, v. 31, n. 1, p. 127-156, 2001-2002.

25. CAPPONI, Giovanna. The garden and the market: human-environment relations and collective imaginary in Afro-Brazilian candomblé between Italy and Brazil. Studia Religiologica, Cracóvia, v. 51, n. 3, p. 165-178, 2018.

26. CAPPONI, Giovanna. Comparative ethnographies of Candomblé rituals in Italy and in Brazil. Antropolítica, Niterói, n. 48, [2020?]. No prelo.

27. CAPUTO, Stela Guedes. Educação nos terreiros e como a escola se relaciona com crianças de candomblé. Rio de Janeiro: Pallas, 2012.

28. CARNEIRO, Patrício. Candomblé sem sangue? pensamento ecológico contemporâneo e transformações rituais nas religiões afro-brasileiras. Curitiba: Appris, 2019.

29. CASTELLS, Manuel. The greening of the self: the environmental movement. In: CASTELLS, Manuel. The power of identity. Hoboken: Wiley-Blackwell, 1999. p. 113-133.

30. CORRÊA, Roberta. O sagrado à porta fechada: (in)visibilidade das religiões de matriz afro-brasileira no campo religioso português. 2016. Tese (Doutorado em Antropologia) - Universidade Federal Fluminense, Niterói, 2016.

31. DUARTE, Luiz Fernando Dias. Romanticism. In: GOOREN, Henri (ed.). Encyclopedia of Latin American religions: religions of the world. Cham: Springer, 2019. p. 1-9.

32. DUBAR, Claude; LALOY, Erik; THOEMMES, Jens; PAIVA, Vanilda (org.). A reforma de vida: a busca de uma outra modernidade. Rio de Janeiro: Jaquatirica, 2015.

33. ESPÍRITO SANTO, Moisés. A religião popular portuguesa. Lisboa: A Regra do Jogo Edições, 1984.

34. FAVRET-SAADA, Jeanne. Deadly words: witchcraft in the Bocage. Cambridge: Cambridge University Press, 1977. 
35. FERREUX, Marie-Jeanne. Le New-Age: ritualités et mythologies contemporaines. Paris: L'Harmattan, 2000.

36. FRIGERIO, Alejandro. El futuro de las religiones mágicas en Latinoamérica. Ciências Sociais e Religião, Porto Alegre, v. 1, n. 1, p. 51-88, 1999.

37. GILROY, Paul. O Atlântico negro. São Paulo: Editora 34, 2001.

38. GINZBURG, Carlo. História noturna. São Paulo: Companhia das Letras, 2012.

39. GOLFETTO, Tatiana. Candomblé Ketu in Italy: dialogues and adaptations. Studia Religiologica, Cracóvia, v. 51, n. 4, p. 265-278, 2018.

40. GOLFETTO, Tatiana. O candomblé na Europa: fluxos e refluxos entre Brasil, Itália e Portugal. Antropolítica, Niterói, n. 48, [2020]. No prelo.

41. GRACINO JÚNIOR, Paulo. "O malandro, o protestante e o galego": uma parábola sobre a transnacionalização do pentecostalismo brasileiro em Portugal. Interseções, Rio de Janeiro, v. 14, n. 1, p. 72-104, 2012.

42. GUILLOT, Mäia. Bruxaria, catholicisme populaire et religions afro-brésiliennes: réflexions sur l'adaptation du candomblé et de l’umbanda au champ religieux portugais. In: CAPONE, Stefania; ARGYRIADIS, Kali (ed.). La religion des Orisha: un champ social transnational en pleine recomposition. Paris: Hermann, 2011. p. 99-135.

43. HAGEDORN, Katherine. From this one song alone, I consider him to be a holy man: ecstatic religion, musical affect, and the global consumer. Journal for the Scientific Study of Religion, Hoboken, v. 45, n. 4, p. 489-496, 2006.

44. HEELAS, Paul. The New Age movement: the celebration of the self and the sacralization of modernity. Oxford: Blackwell, 1996.

45. KIRCHGRABER, Renate Foitzik. Lebensreform und Kunstlergruppierungen um 1900. 2003. Dissertação (Doutorado em História da Filosofia) - Universidade de Basileia, Zurique, 2003.

46. KRABBE, Wolfgang R. Lebensreform/Selbstreform. In: KERBS, Diethart; REULECKE, Jürgen (org.). Handbuch der deutschen Reformbewegungen 1880-1933. Wuppertal: Peter Hammer Verlag, 1998. p. 74.

47. KRESZMEIER, Astrid Habiba. Systemische Naturtherapie. Heidelberg: Carl-Auer Verlag, 2008.

48. KUNDERA, Milan. A imortalidade. Rio de Janeiro: Nova Fronteira, 1990.

49. LE GOFF, Jacques. As raízes medievais da Europa. Petrópolis: Vozes, 2007.

50. LEVACK, Brian. A caça às bruxas: na Europa no limiar da Idade Moderna. Rio de Janeiro: Campus, 1988. 
51. LEWIS, James R.; MELTON, John Gordon. Perspectives on the New Age. Nova York: State University of New York, 1992.

52. LINSE, Ulrich. Das “natürliche” Leben. Die Lebensreform. In: DÜLMEN, Richard van (org.). Die Erfindung des Mensche: Schöpfungsträume und Körperbilder 1500-2000. Böhlau: Wien, 1998. p. 435-456.

53. LINSE, Ulrich. Geisterseher und Wunderwirker: Heilssuche im Industriezeitalter. Berlim: Fischer Taschenbuch Verlag, 1996.

54. LOPES, Aurélio. Religião popular no Ribatejo. Santarém: Assembleia Distrital de Santarém, 1995.

55. LOWY, Michael. Revisitações do Romantismo: entrevista com Michael Lowy. In: COHN, Sergio; CESARINO, Pedro; REZENDE, Renato. Azougue: edição especial 2006-2008. Rio de Janeiro: Beco do Azougue, 2008. p. 15-21.

56. MARTINS, José Garrucho. As bruxas e o transe: dos nomes às práticas. Vila Nova de Gaia: Estratégias Criativas, 1997.

57. MEYER, Birgit; WITTE, Marleen de. Heritage and the sacred: introduction. Material Religion, v. 9, n. 3, p. 274-280, 2013.

58. MONTENEGRO, Miguel. Les bruxos: des thérapeutes traditionnels et leur clientèle au Portugal. Paris: L'Harmattan, 2005.

59. ORO, Ari. As religiões afro-brasileiras: religiões de exportação. In: AFRO-AMERICAN RELIGIONS IN TRANSITION. INTERNATIONAL CONFERENCE OF THE AMERICANISTS. 1998. Uppsala. Anais [...]. Uppsala, 1998. Mimeografado.

60. PORDEUS JÚNIOR, Ismael. Portugal em transe: transnacionalização das religiões afro-brasileiras: conversão e performances. Portugal: Instituto de Ciências Sociais da Universidade de Lisboa, 2009.

61. ROSSBACH DE OLMOS, Lioba. Santeria abroad: the short history of an Afro-Cuban religion in Germany by means of biographies of some of its priests. Anthropos, Barcelona, v. 104, n. 2, p. 483-497, 2009.

62. SÁNCHEZ, Marcela. El cielo en la tierra. Jornada Semanal, [s. l.], 25 mar. 2001. Disponível em: https://bit.ly/2T2cF8w. Acesso em: 29 nov. 2019.

63. SARAIVA, Maria Clara Ferreira de Almeida. Afro-Brazilian religions in Portugal: bruxos, priests and pais de santo. Etnográfica, Lisboa, v. 14, n. 2, p. 265-288, 2010.

64. SARAIVA, Maria Clara Ferreira de Almeida. Blood, sacrifices and religious freedom: afro-brazilian associations in Portugal. In: MAPRIL, José; BLANES, Ruy Llera (ed.). Site and politics of religious diversity in Southern Europe: the best of all gods. Leiden: Brill, 2013. p. 129-154. 
65. SEGATO, Rita Laura. Cambio religioso y desetnification: la expansión evangélica en los Andes centrales de Argentina. Religiones latinoamericanas, Saler, v. 1, p. 137-173, 1994.

66. SEGATO, Rita Laura. Formação de diversidade: nação e opções religiosas no contexto de globalização. In: ORO, Ari Pedro; STEIL, Carlos Alberto (org.). Globalização e religião. Petrópolis: Vozes, 1997. p. 219-248.

67. SEGATO, Rita Laura. Uma vocação de minoria: a expansão dos cultos afro-brasileiros na Argentina como processo de reetnização. Dados, Rio de Janeiro, v. 34, n. 2, p. 249-278, 1991.

68. SILVA, Inga Scharf da. Naturgeschichte, Körpergedächtnis Erkundungen einer kulturanthropologischen Denkfigur. Konnex: Studien im Schnittbereich von Literatur, Kultur und Natur. In: BARTL, Andrea; SCHOTT, Hans-Joachim (org.). Trauma als Wissensarchiv: Ambivalenzen zwischen Kollektivem Bildgedächntnis und Verkörperungen am Beispiel der Caboclas und Caboclos in der Umbanda. Würzburg: Königshausen \& Neumann, 2014. p. 271-293.

69. SOUZA, Laura de Mello e. O diabo e a Terra de Santa Cruz: feitiçaria e religiosidade popular no Brasil colonial. São Paulo: Companhia das Letras, 1986.

70. SPLIESGART, Roland. Brasilianische Religionen in Deutschland. In: KLÖCKER, Michael; TWORUSCHKA, Udo (org.). Handbuch der Religionen: Kirchen und andere Glaubensgemeinschaften in Deutschland. Munique: Ergänzungslieferung, 2011. v. II, p. 27.

71. STOLLER, Paul. The taste of ethnographic things: the senses in anthropology. Filadélfia: University of Pennsylvania Press, 1989.

72. TEISENHOFFER, Viola. Umbanda, New Age et psychothérapie: aspects de l'implantation de l'umbanda à Paris. Atéliers d'anthropologie, Nanterre, v. 31, 2007.

73. TREITEL, Corrina. A science for the soul: occultism and the genesis of the German modern. Baltimore: The Johns Hopkins University Press, 2004.

74. WEBB, James. The occult underground. Illinois: Salle, 1974.

75. Medicina antroposófica. Weleda, São Paulo, [s. d.]. Disponível em: https://bit.ly/2TohAQa. Acesso em: 29 nov. 2019. 